\title{
AC 2007-1222: IMPROVING STUDENT INTUITION VIA RENSSELAER'S NEW MOBILE STUDIO PEDAGOGY
}

Don Millard, Rensselaer Polytechnic Institute

Mohamed Chouikha, Howard University

Frederick Berry, Rose-Hulman Institute of Technology 


\title{
“IMPROVING STUDENT INTUITION VIA RENSSELAER'S NEW MOBILE STUdio PEDAgOGY"
}

\author{
DON LEWIS MILLARD, RENSSELAER \\ MOHAMED CHOUIKHA, HOWARD UNIVERSITY \\ FREDRICK BERRY, ROSE-HULMAN INSTITUTE OF TECHNOLOGY
}

\section{Motivation AND RELEVANCE}

Although computer literate, today's engineering students don't enter college with the same level of hands-on experience with hardware that prior generations exhibited. Experimentation provides students with a sense of where things deviate from theory, offering the opportunity to explore non-ideal conditions; while also giving them the chance to play with hardware and gain the experience and expertise that helps them become successful designers. ${ }^{1,2}$ For example, electronics technicians who had vast hands-on experience were able to reproduce large portions of complex circuit diagrams after only a few seconds of viewing; whereas novices could not. ${ }^{3}$ This was due to their ability to chunk the individual circuit elements that functioned together as an amplifier. Expert scientists and engineers are able to quickly recognize patterns of information; for example, physicists recognize problems of river currents and problems of headwinds and tailwinds in airplanes as involving similar mathematical principles, such as relative velocities. ${ }^{4}$ Gone are the days when students were ham radio operators, played with Erector/LEGO sets, tinkered with electronic kits or simply taken things apart for fun. As a result, students have less "gut intuition" and expert skills than prior generations possessed when entering the job market. ${ }^{5}$

\section{Studio Pedagogy}

The defining characteristics of studio classes are an integrated lecture-laboratory format, a reduced amount of time allotted to lecture; a technology-enhanced learning environment, collaborative group work and a high level of faculty-student interaction. The studio environment historically has employed activities, computer tools, multimedia materials and expensive instrumentation that allow students to actively participate in their own learning and to construct scientific knowledge. A high priority is placed on allowing students to learn directly from their interactions with the physical world through hands-on activities. At the time of its initial incorporation in physics courses at Rensselaer in 1994, this approach had several advantages over the traditional lecture-recitation-laboratory method:

- Learn and Apply: Studio eliminated the time separation between the students' hearing the information and applying it in laboratory. The original Studio concept allowed for approximately one hour of lecture and homework discussion, which was immediately followed by an activity where students solved paper-and-pencil problems, investigated computer simulations, or conducted hands-on experiments.

- Access to Professors: The entire class was taught and supervised by a Ph.D. faculty member. Previously, the professor-in-charge had contact with the students only through the lecture portion in which the entire enrollment met in a large lecture hall. Recitation (discussion) and 
laboratory classes, where student-instructor interaction was more easily fostered, were taught by teaching assistants (TA's); some of whom had a poor grasp of English, thus making them less approachable. Studio offered students a far greater opportunity to interact one-on-one with the professor.

- Instrumentation Potential: User-friendly, computer-controlled instrumentation and data analysis techniques have revolutionized the way measurements are made. Studio instrumentation allowed nearly instantaneous comparison between theoretical predictions, simulations, and actual experimental results. ${ }^{6}$

\section{STUDENT FOCUS: IsSUES \& NEEDS}

Today we depend on computers and the Internet to do our jobs, yet we have only begun to scratch the surface of using technology to improve education. ${ }^{7,8,9}$ Even with such advances, we need to incorporate more practical examples, illustrative materials, and engaging hands-on activities that reach and motivate the diverse groups of today's students. ${ }^{10}$ We now have the potential to identify a student's learning style ${ }^{\mathbf{1 1}}$ and difficulties in grasping concepts, thus allowing us to deliver education in more effective ways. ${ }^{12}$ Educators need to provide supplemental hands-on components so that visual/tactile learners can garner an understanding of the material, while stronger students can explore activities in greater depth to maintain interest. ${ }^{13,14}$ Even today's most successful courses, regardless of format, can take advantage of recent advances in cognitive science $^{\mathbf{1 5}}$, learning research ${ }^{\mathbf{1 6}}$, and educational technology to help address the following issues:

- Computer Savvy Students: When the concept of Studio was originally implemented, it dramatically reduced the number of in-class demonstrations which previously were hallmarks of the introductory courses at Rensselaer-predominantly due to space limitations. These were replaced, in part, by computer simulations that were innovative at the time and used an emerging technology which captured student's interest; but today's student has grown up with computers. Demonstrations and laboratories performed on computers fail to capture the students' interest as they once did. We hypothesize that because students spend so much of their time playing with computers as children, today's students are very savvy with software, but seem to be less aware of real-world phenomena. ${ }^{17}$

- Attention Span: We have observed a diminished ability for students to stay focused and pay attention in class. Even the dramatically reduced "lecture" portion of our studio classes is less effective than it once was. It is well supported by educational research that humans retain perhaps $10 \%$ of what they hear someone else tell them, but retain as much as $90 \%$ of what they learn by doing. ${ }^{18}$

- Demands on Students' Time: Student attention span and consciousness in class is also problematic due to the highly emphasized social aspect of the university environment (i.e. email, IM, etc.). Many of today's students seek a "college experience" composed of a vast number of extracurricular activities, not just instruction in academic subjects. Formal education is consuming a smaller percentage of their time. Additionally, project-based courses require a great deal of out-of-class team meeting time, often late at night.

- A Shortage of Hands-on Exploration: Pre-exposure to technical concepts is far less uniform among students from increasingly diverse educational and cultural backgrounds than it was a decade ago. Gone are the days when the majority of STEM-inclined students were ham radio operators, played with Erector/LEGO sets and had tinkered extensively 
with electronic kits—or simply taken things apart. Variance in learning styles requires attention to individual talents and weaknesses. ${ }^{19}$

"Studio teaching" improved the quality of engineering education at Rensselaer and has since been adopted, in various forms, by many other universities. However, after more than ten years we now need to make modifications that can better serve today's generation of students. We have identified the following specific opportunities for improvement:

- More Closely Couple Lectures with Hands-On Activities: Education research has made it clear that large-scale lectures, regardless of the quality of the instructor, are inefficient vehicles for learning. The lecture format gives the appearance of being cost-effective, yet students are learning little, if they attend. Small classes promote learning, but are costprohibitive in large enrollment courses associated with core introductory engineering education. ${ }^{20}$ Studio does not eliminate the lecture portion of the class, yet a majority of students do not pay attention or retain much of what they hear in the lecture or during the homework review. Therefore, any part of the class where students merely sit and attempt to listen passively - will be less effective than when they are actively engaged.

- Make Better Use of Existing Facilities: Studio classrooms are often crowded, with 40 or more students, the professor, and two TAs occupying slightly over 1,000 square feet. Spaces to undertake hands-on activities are limited, so that some of the activities cannot be done comfortably in the allotted areas. The available laboratory equipment that can be used is also limited by other classes using the same rooms, requiring the equipment to be both frequently installed and removed. Since we must live with these limitations, the challenge for technical education is to develop a novel, compact and portable means to allow for the hands-on learning of concepts in minimal classroom spaces - while further expanding the opportunities to experiment outside the classroom as well.

- Extend the Time Available for Activity/Laboratory: In the studio format, the activity portion can last from 40 to 50 minutes. This is insufficient time for the students to do any sort of probing, meaningful experiments. Activities are therefore constrained to covering a few main points at a superficial level. Even so, the slower student teams struggle to finish the activities in the allotted time and often wind up missing the main points in an effort to complete the detailed steps in the activity instructions.

- Require Active Participation of ALL Students: Even when student teams are able to finish on time, we often find that some team members are content to passively watch and record data while the "alpha" team member handles the equipment and takes data. While working in a team is an important skill, each student also needs individual practice setting up equipment, taking data, and troubleshooting in order to reach his/her full potential as a technical professional.

- Overcome Equipment Limitations: Much of the hands-on equipment that is used in studio makes extensive use of wiring to connect the components of the experiments. The equipment and components are unwieldy, and take up an inordinate amount of space on a table top. Students using these set-ups have as little as a few inches of remaining space for books, notebooks and writing space. In addition, the wire connections and limited space significantly interfere with the data taking process in many experiments, yielding results that are not fully consistent from the students' perspective with the principles being taught. 
- Provide More Hands-On Equipment: Some of the activities (that do not use equipment) simply make use of outdated computer simulations or are entirely pencil-on-paper problems. These activities could greatly benefit from physical experiments that take advantage of Rensselaer's newly developed very low-cost, signal acquisition, monitoring and control instrumentation/equipment (Mobile Studio Instrumentation Board - described below).

\section{THE MobiLe STUdio ConCEPT}

Rensselaer has begun to examine the potential for creating instrumentationbased Mobile Studio environments that are flexible, re-configurable, and location independent (e.g. anywhere on/offcampus) - which was recently described in the December 2006 ASEE Prism Magazine. With the advent of mobile technology, the collaborative learning milieu can now expand beyond the campus classrooms - to the dorms - and the rest of the university spaces. This project will leverage Rensselaerdeveloped hardware and software (shown in the bottom panes of figure 1) which, when connected to the PC via a USB port, provides similar functionality to that of the laboratory equipment currently associated with an instrumented studio classroom (exhibited in the top panes of
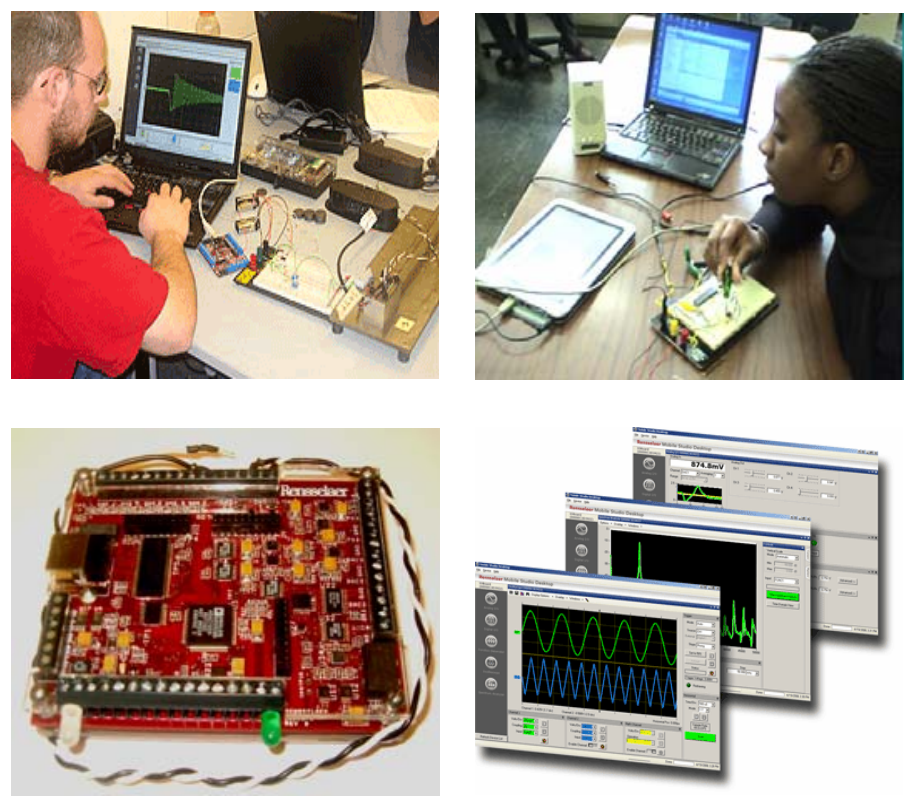

Figure 1: Rensselaer's Mobile Instrumentation Board (100KS/s version) and Hardware/Software Environment

\section{figure 1). This Mobile Studio}

Instrumentation Board (I/O Board) technology replicates the functionality of an oscilloscope, function generator, multimeter, power supplies and additionally allows users to control external devices with 16 reconfigurable digital I/O ports. With the advent of a Mobile Studio lab, many instrumentation-based course offerings could be held in normal classrooms rather than in specially outfitted studio facilities. In addition, students will be able to perform hands-on experiments outside of the classroom anywhere/anytime, thus facilitating new opportunities for them to explore/tinker and gain insight through practical experience.

The Mobile Studio Instrumentation Board (version 1 of which is shown in the bottom left pane of figure 1) educational technology and the Mobile Studio pedagogy have been under development at Rensselaer since fall 2004. In order to first investigate the extension of the pedagogy \& educational technology to a different/diverse campus, two test Mobile Studio sessions (involving one class each) were conducted at Howard University in 2005 using the Mobile Studio setup. Since Howard does not currently have studio facilities, the sessions offered their students a hands-on experience - in contrast with what had typically been purely paper and pencil projects. The formal evaluation of these sessions indicated that student learning was positively impacted. ${ }^{21}$

Pilot Mobile Studio PC-based classes in engineering courses were then conducted at Rensselaer, Howard and Rose-Hulman during the spring and fall 2006 semesters. The student response from the limited pilot classes has been tremendous - uniformly generating requests for 
such activities to be inserted throughout the entire course. Additionally, students are now able to use the I/O board to work on design projects outside of class (e.g. in the union/dorm - an example of which is included in the supplementary materials). Two outreach activities were carried out with $4^{\text {th }}$ grade science teachers from the Niskayuna, New York School District. Tablet PCs were used to explore interactive modules (developed by Rensselaer's Academy of Electronic Media) along with the Mobile Studio Instrumentation Board in a physical demonstration to aid the students' understanding of electrical connectivity, resistance and circuit testing.

\section{Mobile Studio Pedagogy}

Considering all of the issues and constraints involved with the present-day studio classroom described above, a logical improvement would be to utilize hardware which is small, portable and adaptable to a wide variety of hands-on experiments/environments. Using the Mobile Studio Instrumentation Board, students can simultaneously produce/analyze waveforms that can be connected (as the input) to a system; acquire/capture, investigate/measure signals; and record data, organize \& distribute notes, schematics, measurements and observations to those participating in the class. When complimenting an in-class activity, they will supplement whatever hands-on experiments by allowing the use of a different approach of measurement and additional permutations and exploration. The Mobile Studio I/O boards are used to provide hands-on experimentation in the classroom and then be taken home by the student to continue the hands-on activity on their own time - outside of the classroom.

Rensselaer has been developing an experimentation-centric, Mobile Studio pedagogy to provide students with further hands-on opportunities that help solidify the "big ideas" and design insight associated with engineering. We are exploring and assessing the proper "mix" of lecture, paper \& pencil, computer module and experimental activities that best helps the student to grasp the fundamentals and achieve the desired learning outcomes. These new templates of multimodal activities will continually be evaluated and refined throughout the project and will ultimately be disseminated in a manner similar to that which Rensselaer's original studio model was introduced, adapted and since adopted by others.

David Kolb found that the four combinations of perceiving and processing determine the four learning styles. According to Kolb, the learning cycle involves four processes that must be present for learning to occur: 1) Active Experimentation (protoboards, simulations, case study, homework), 2) Reflective Observation (logs, journals, brainstorming), 3) Abstract Conceptualization (lecture, papers, analogies), and 4) Concrete Experience (laboratories, field work, observations). This project is investigating the impact on student learning outcomes produced by incorporation of the Mobile Studio pedagogy in courses that will be delivered using the Kolb cycle to sequence the courses' activities as follows:

1. Students are introduced to topics and are then asked to formulate hypotheses and plan/perform experiments to determine the validity of their intuition.

2. The students relate their outcomes to real-life applications and provide a sense as to how their results could be further utilized.

3. The students present their findings and, alternatively, watch other's presentations; ultimately using Tablet PCs to sketch, review and document their perspectives, understandings, visualizations and conclusions.

4. Finally, they will apply the results in developing a design to more open-ended problems/questions; again using the Tablets as a means to help capture ("an electronic 
cocktail napkin"), view, communicate, and present their ideas and solutions; thereby completing the revolution around the Kolb cycle.

After an instructor led demo, the students are given a statement of the problem to be explored or the quantities to be measured. The instructor assists students (in class) to devise a basic experimentation plan and to make sure their equipment is working properly. The students then fill in the details of their plan, acquire the data, and analyze it on their own. This offers the students an opportunity to perform the experiment without being fully guided through a "cookbook" exercise. Results are discussed in class (during the next session) to ensure that the students have learned the principles that the experiment was designed to teach. Design-oriented projects are then assigned to provide students with a guided activity to help them synthesize and apply the concepts.

Because of the increased time outside of class to complete these experiments, we have modified the associated assigned homework problems so that they are closely matched with the data analysis the students need to perform using the Mobile Studio equipment. Too often, students think of homework problems from the textbook as abstract mathematical puzzles having little to do with the real world. We want to encourage the students to think about the physical phenomena that they have just observed when solving homework problems; conversely, we want to encourage them to use the mathematical techniques behind the homework problems to analyze and understand their data. We have since adapted our grading scheme so that students are not afraid to fail when they work on an experiment, allowing them to correct their errors before handing in their final write-up.

The Mobile Studio allows professors and students to review and annotate each other's acquired signals and figures, while additionally providing a means to record the entire session using Tablet PCs (provided by HP as part of education grant) and the student laptops. The Mobile Studio enables faculty from resource-limited community colleges and under-represented minority institutions (e.g. Community Colleges, HBCUs, etc.) to establish a low-cost, instrumentation-rich studio classroom in any space on campus, offering the potential to examine a question via an impromptu, hands-on hardware demonstration/activity.

\section{CURRENT Mobile Studio DeVELOPMENT}

Pilot Mobile Studio based demonstrations, in-class activities, and follow-up take-home experiments have been designed, developed, utilized, evaluated and disseminated for each of the two courses (Circuits, Electronics and Instrumentation). In the full deployment, there will be either a hands-on physical demonstration and/or class activity every day of the semester. The Mobile Studio Instrumentation board will allow students to record, process, and tailor the signal(s) they are measuring. The following specific examples are included to give the reader a sense of what kinds of activities are performed by the students.

Circuit Response - The relationships among first and second order time/frequency response, damping, resonance and filtering are investigated via a number of experimental activities. A faculty demonstration first introduces the correspondence between a circuit's component values (RL, RC, RLC) by varying the components while students observe the impact on the output waveforms (acquiring them using the I/O board - from the representative input signals $\left\{\mathrm{V}_{\text {in }}\right\}$ produced by the I/O board's function generator: switched $D C$, sine, square) that are displayed using a projector and the instructor's computer. Students are then asked to experimentally determine the resistor's value that is needed to produce a critically damped response for a given $\mathrm{L}$ and $\mathrm{C}$ connected in series (and later in parallel) and compare the result with the theoretical 
calculation (e.g. considering the added resistance of the wires, inductance winding, etc.). For "hardware-based" homework, students are given a specific "unknown" inductor and asked to find the following:

1. The value of the inductance using a known resistor in a series RL circuit

2. Experimentally determine what value of Capacitance $(C)$ would be needed to generate both an over-damped and under-damped natural response

3. Verify the value of the unknown inductor using the under-damped response waveform captured with the I/O board and Excel (from the Mobile Studio's export feature) correlated with the $2^{\text {nd }}$ order mathematical quantities (zeta, $\omega_{0}$, BW and Q)

4. Determine the relationship between resonance, $\mathrm{Q}$ and damping from experimenting with different component values - exploring the impedances and voltages/currents associated with a resonant condition, along with its potential application as a band pass/stop filter

5. Explore the correlation between the time and frequency domain responses; changing the component values and observing the effect on the bandwidth, cutoff frequency, phase shift and filter response (experimenting with taking the output across the $\mathrm{R}, \mathrm{L}$ and $\mathrm{C}$ )

6. As a culminating exercise for students to synthesize these concepts, they are asked to develop and perform experiments to determine where an extraneous band of noise is corrupting a desired audio signal (from either an electric guitar or mp3 player). Based upon their results, they design, develop and test a (notch) filter circuit to reduce the noise. The students create their circuits with the aid of the Filters CAD and Pole/Zero interactive modules (www.academy.rpi.edu) using the Mobile Studio Instrumentation Board to then test and evaluate their designs. Then the students document, present and publish their results (correlated with the mathematical analysis); along with the observations of the other class members in an on-line portfolio.

Power Factor Correction - This exercise is intended to help students understand how the power factor (pf) can be improved and how the improved pf impacts an electrical supply. First the students watch a demonstration and then build a RL parallel circuit and measure the current drawn from the supply and the voltage drop across the elements (using a shunt resistor to measure supply current) - in class. The phase shift between the voltage and the supply current is then measured using the scope. Once the phase shift between the current and voltage are measured - the real power, reactive power, apparent power, and the $\mathrm{pf}$ at the load will be calculated and verified by the student using Rensselaer's Academy of Electronic Media (www.academy.rpi.edu) pf correction learning module. Then, for homework, the students are asked to add a capacitor to the parallel circuit and experimentally determine the value of $\mathrm{C}$ that would produce a $\mathrm{pf}=.90$ lagging. Ultimately, a subsequent in-class review of the results leads to a discussion on pf stability and how to improve power system efficiency - including an in-class follow-up demonstration to help further visualize and reinforce the concept.

Benefits of a full deployment of Mobile Studio:

- Every Student Will Participate - Every student will be able to have a Mobile Studio Instrumentation Board to do a home lab individually, both in and out of class, eliminating the requirement to work in groups due simply to equipment limitations. (We will of course retain teamwork where it makes pedagogical sense.) 
- Intimidation is Eliminated -Homework often reduces to students looking for formulas to plug numbers into (template matching), thereby minimizing its effectiveness. A take-home laboratory in addition to traditional (and new synergistic) homework will provide further opportunity for students to learn about real-world applications. Students will not feel intimidated by peers or professors; not to mention the clock. In short, their natural inquisitive instincts will be encouraged to reappear without the fear of failure.

- Individualized Experiments - In the classroom, largely due to time constraints, students typically follow a step-by-step set of instructions to take measurements. This "cookbook" method allows for no creativity. With a take-home lab, we envision giving students a statement of the problem to be explored or the quantities to be measured and then taking on the role of an advisor in class - as they devise their own procedures to acquire and analyze the data (which they will begin in class and later complete as homework). This will offer the students an opportunity to experience being "real" scientists and engineers (possibly for the first time); where they are not held by the hand throughout the laboratory.

- Inexpensive - The Mobile Studio Instrumentation Board is projected to be roughly $\$ 130$. This is about the cost of a textbook. It is a device that the students would own throughout their entire undergraduate career, and have applications beyond that of a particular class. For instance, the device could be used as a multimeter, scope or a controller (using the digital I/O in conjunction with the analog $\mathrm{I} / \mathrm{O}$ ); providing a highly useful project tool (signal processor/controller) for any individual studying to become a scientist or engineer.

\section{EVALUATION}

The following research questions are currently being tested and evaluated in diverse situations in the Circuits (for majors), and Electronics \& Instrumentation (for non-majors) courses at each of the partnering schools to study the resulting impact on student learning:

- What type, sequence, mode and repetition of activity best supports long term retention (e.g. lecture-problem solving-experimentation-synthesis; experimentation-problem solvinglecture-synthesis; in-class lecture-experimentation-problem solving-synthesis-out-of-class experimentation; etc.)?

- What mixture of constrained and open-ended experimentation allows students with differing backgrounds and ability to fill-in and support gaps in basic theory or visualization of principles/applications?

- Does the Mobile Studio pedagogy impact those categorized by one learning style more so than others? Are specific categories (Active/Reflective, Sensing/Intuitive, Visual/Verbal, and Sequential/Global) impacted differently by varying amounts of activity and sequencing?

- How long (and how often) an exposure to material is necessary to insure that concepts are retained by all (regardless of sensory preference)?

- How does follow-up exploration outside of class effect students' ability to formulate experimentation strategies to test other hypotheses?

- How does the Mobile Studio pedagogy allow instructors to better relate the benefits of scaffolding (using the Kolb cycle) to better address the various ways students learn? What further impact can be produced using the Mobile Studio Instrumentation Board out of class to complete multiple revolutions around the Kolb cycle? 
Evaluators (from the Evaluation Consortium-located within the University at Albany) are helping assess the project and its implementation effect (as they have done on numerous joint NSF projects with Rensselaer over the past 10 years). They conduct formative evaluation on a continuing basis, commencing in the beginning and continuing throughout the project. Assessments will focus on identifying intermediate success, programmatic weakness and areas in need of modification or alteration; as the Mobile Studio educational materials, technology, practices, in-class and out-of-class templates are developed, implemented and fully tested. Feedback from the consultants is regularly provided to the faculty, supported by a written report and workshops each semester (as was done in the prior projects). Summative evaluation focuses on short-term and long-term learning, transfer of knowledge to other engineering courses, and transfer of ability to use the new methodologies across content. Data is collected from both faculty and students using the materials.

\section{COMPARISON WITH COMMERCIALly AVAILABLE EQUIPMENT}

There are a number of similar products that are commercially available. However, none of them offer the full set of Analog/Digital Input/Output functionality provided by the Mobile Studio Instrumentation board - especially at a price of approximately $\$ 80-\$ 90$ (20 kHz version) to $\$ 130$ (2 MHz version) AND small form factor (3" x 3"). For example, National Instruments (e.g. ELVIS), Pasco, Vernier, EMONA (tims) and others have a number of Data Acquisition products geared for the educational environment; yet the current offerings are either significantly less portable (even requiring a separate power supply), are more expensive ( $>\$ 500$ - to well over $\$ 2,000)$, don't offer the full set of features, and/or utilize significantly lower sampling rates; since they are primarily intended for use as a data logger (e.g. $48 \mathrm{KS} / \mathrm{sec}$ vs. approximately $30 \mathrm{MS} / \mathrm{sec}$ for the current version 2, $\$ 130 \mathrm{I} / \mathrm{O}$ board) with minimal control capabilities. The Mobile Studio Instrumentation Board was specifically designed to be used in conjunction with science and engineering courses that currently involve numerous individual pieces of equipment which require large space allocations and, therefore, dedicated facilities. It is meant to serve as an extremely affordable, general-purpose instrumentation suite that is capable of being used by students with their PCs, protoboards, etc. - anywhere, at anytime.

\section{CONCLUSIONS}

Notwithstanding the recent advances in educational technology, we still need to incorporate more dynamic, hands-on opportunities to reach and motivate more diverse populations. ${ }^{22,23,24}$ Today's students do not enter college with the same amount of practical experience that prior generations had. ${ }^{25,26}$ Ultimately, we can enable scaffolding and improve retention of concepts using interactive computer based hardware/software, since users can guide themselves through materials and explore at their own pace and level. ${ }^{27,28,29}$ Therefore, it is our hope and goal that a low-cost, experimentation centric pedagogy that allows faculty and students to implement laboratory instrumentation based Mobile Studio environments anywhere (classroom, library, union, dorm, etc.), at anytime (24/7) will significantly enhance STEM education. 


\section{REFERENCES}

1. Sechrist, Chalmers F., "Wanted: A Few Good Engineers", The Interface, Published jointly by IEEE and ASEE, August 1998, Number 2.

2. R.M. Felder and L.K. Silverman. "Learning Styles and Teaching Styles in Engineering Education." Engr. Education, 78 (7), 674-681, 1988.

3. Egan D.E., Schwartz B.J., "Chunking in recall of symbolic drawings" Mem Cognit. 1979 Mar; 7(2):149-58.

4. Chi, M., Glaser, R., "Categorization and Representation Physics Problems by Experts and Novices", Cognitive Science 5, 121-152., 1988.

5. Sechrist, Chalmers F., "Wanted: A Few Good Engineers", The Interface, Published jointly by IEEE and ASEE, August 1998, Number 2.

6. Cummings, K. and T. French. 2001. Development of a Problem Solving Assessment Tool for Introductory Physics Students, Proceedings of the National Physics Education Research Conference, (2001).

7. "Engineering Education and Practice in the United States," National Academy Press, 1985.

8. McKenna, A. \& Agogino, A. (1998) A Web-based Instructional Module for Teaching Middle School Students Engineering Design with Simple Machines. Paper presented at the annual meeting of the American Educational Research Association, San Diego.

9. M. Kadiyala and B.L. Crynes, "A Review of Literature on Effectiveness of Use of Information Technology in Education," J. Engr. Education, 89(2), 177-189, 2000.

10. D.A. Kolb, Experiential Learning: Experience as the Source of Learning and Development. Englewood Cliffs, NJ, Prentice-Hall, 1984.

11. R.M. Felder and L.K. Silverman. "Learning Styles and Teaching Styles in Engineering Education." Engr. Education, 78 (7), 674-681, 1988.

12. Bransford, John. D, A. L. Brown, and R. Cocking, eds. "How People Learn," NAC Press, Washington, D.C., 1999.

13. "Quality of Engineering Education," Final Report of the Quality of Engineering Education Project, American Society for Engineering Education, September 1986.

14 The Engineer of 2020: Visions of Engineering in the New Century, The National Academy of Engineering, 2004.

15. Hillocks, G. (1999). Ways of Thinking/Ways of Teaching. New York: Teachers College Press.

16. Bransford, John. D, A. L. Brown, and R. Cocking, eds. "How People Learn," NAC Press, Washington, D.C., 1999.

17. Kandiah Manivannan and David E. Meltzer, Use of In-class Physics Demonstrations in Highly Interactive Format, Proceedings of the Physics Education Research Conference, Rochester, New York, July 25-26, 2001, edited by Scott Franklin, Jeffrey Marx, and Karen Cummings (Rochester, New York, 2001), pp. 95-98.

18. Lu, Toh-Ming, "Turmoil and Opportunities in Higher Education"-The road of an Academic Department at the Dawn of the 21st Century, Integrated Book Technology, Inc, 2000. 
19. F.A. Kulacki and E.R. Krueger, "Trends in Engineering Education - An International Perspective", International Conference on Engineering Education, 1998, Rio de Janeiro.

20. Bransford, John. D, A. L. Brown, and R. Cocking, eds. 1999. How People Learn. NAC Press, Washington, D.C.

21 Thomas, V., Track II: Evaluation of the Tablet PC in Undergraduate Engineering Courses at Howard University, Internal Report to Howard University HP Grant Recipients, 2006.

22. D.A. Kolb, Experiential Learning: Experience as the Source of Learning and Development. Englewood Cliffs, NJ, Prentice-Hall, 1984.

23. R.M. Felder and L.K. Silverman. "Learning Styles and Teaching Styles in Engineering Education." Engr. Education, 78 (7), 674-681, 1988.

24. Jackson, S., "Our emerging crisis: the graying of American science", Research USA, April 28, 2003.

25. Cyr, M., Miragila, V., Nocera, T., Rogers, C. A Low-Cost, Innovative Methodology for Teaching Engineering Through Experimentation. Journal of Engineering Education, Vol. 86, No. 2

26. Kresta, S. (1998) "Hands-on Demonstrations: An Alternative to Full Scale Bench Experiments", Journal of Engineering Education, p. 7-9.

27. Jacobson, M. J., \& Spiro, R. J. (1994). Hypertext Learning Environments, Cognitive Flexibility, and the Transfer of Complex Knowledge: An Empirical Investigation. Journal of Educational Computing Research, 12(4)

28. Vygotsky, L. (1934/1986). Thought and Language, trans. A. Kozulin. Cambridge, MA: Harvard University Press.

29. Linn, M.C. 'Designing Computer Environments for Engineering and Computer Science: The Scaffolded Knowledge Integration Framework, Journal of Science Education and Technology, Vol. 4, No. 2, 1995. 